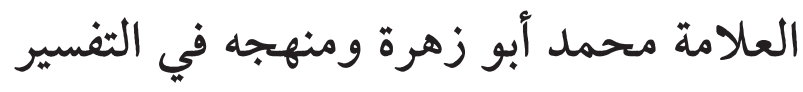

Shahabaddin Amirzadeh SHAMS*

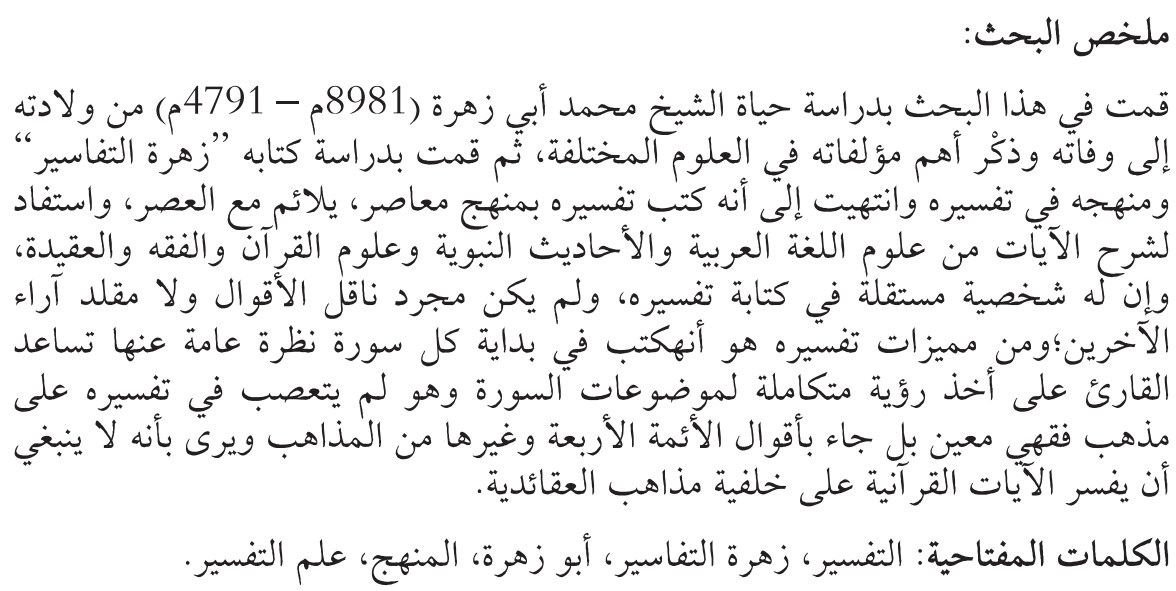

\title{
MUHAMMED EBU ZEHRA VE TEFSİRDEKİ METODU
}

\section{Özet}

Bu çalışmada Şeyh Muhammed Ebu Zehra'nın doğumundan vefatına kadar hayatını ve muhtelif ilim dallarındaki en önemli telif eserlerini inceledik. Netice olarak "Zehratü't-Tefâsir" isimli tefsirini asra uygun bir metot ve dille kaleme aldığı neticesine ulaștım. Ebu Zehra ayetlerin açıklamasında Arap dili ilimleri, Hadis-i Nebevi, Ulumu'l-Kurân, fıkıh ve akaid gibi ilimlerden faydalanmıştır. Tefsirinde sadece bir nâkil veya başkalarının görüşlerini taklit eden bir mukallit olmamış aynı zamanda kendisine has kanaatlerini serdetmiştir. Tefsirinin öne çıkan özelliklerinden birisi, okuyucunun surenin konuları hakkında şâmil bir bakış açısı kazanmasına yardımcı olması için her surenin başında genel bir takdim sunmasıdır. Tefsirini muayyen bir mezhep üzerine ikame etmemiş aksine dört büyük mezhebin ve diğer farklı mezheplerin görüşlerini de hesaba katarak eserini kaleme almıştır. Ayetlerin akidevi arka plana dayanılarak tefsir edilmemesi gerektiğini düşünmektedir.

Anahtar Kelimeler: Tefsir, Zehratü't-Tefâsîr, Muhammed Ebû Zehra, Yöntem, Tefsir İlmi. 
ولا يطنب إطنابا مملاً، فيشرح في بداية السورة موضوعاتها الأساسية حتى يتضح للقارئ تصور

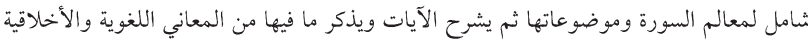
والعقائدية والفقهية حسب الفي ما يراه مناسبا.

وأما عدم إكمال التفسير بسبب وفات المؤلف لا ينقص من قدر الكتاب؛ واشتهاره بين التفاسير

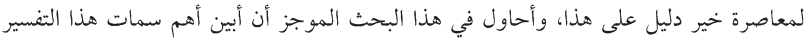

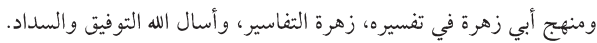

$$
\text { أهمية البحث: }
$$

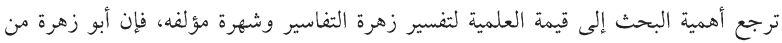

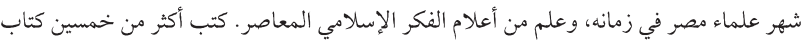

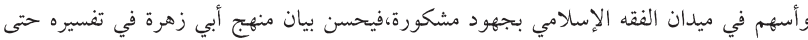

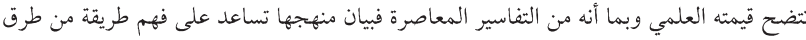

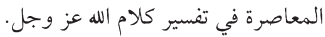

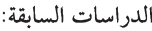

كتبت في منهج الشيخ أبو زهرة مقالات ورسائل جامعية من أبرزها:1-منهج الإمام محمد أبو

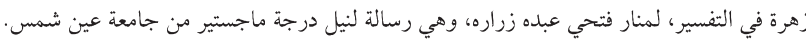

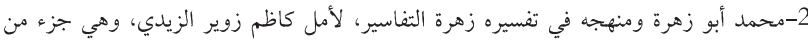

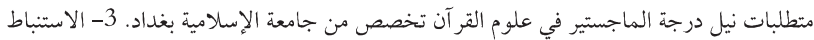

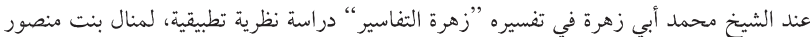

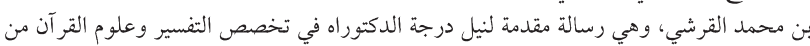

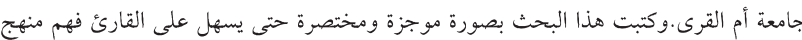

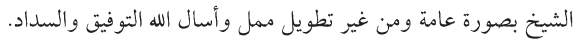

$$
\text { منهج البحث: }
$$

ستتبع هذه الدراسة المنهج الوصفي التحليلي والذي يهتم بتوصيف وشرح منهج أبي زهرة في

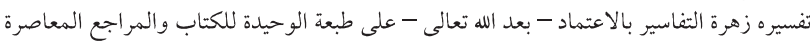

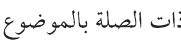$$
\text { طريقة البحث: - مئ }
$$

أسير في البحث بمشيئة الله على المنهج التالي:التعريف بالشيخ أبي زهرة - رحمه الله - ونشأته

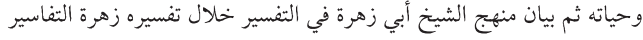

ABU ZAHRAH AND HIS INTERPRETATION

METHODOLOGIES IN ZAHRAT AL-TAFASIR

Abstract

In this research, I studied biography of Sheik Muhammed Abu Zahrah (1898 - 1974 A.D.) from birth to demise including re ports on his most significant writings and compilations in various sciences. Next, I surveyed his book titled Zahrat-al-Tafasir and concluded that he wrote his interpretations based on methodologies that are current and applicable to his own era; and for interpreting verses (ayat) he amployed Arabic langua se inter. tics, Hadith (words of the prophet), Qurans science and jurispruview into his interpretation and does not suffice to quotin words and opinions of the others alone. One of the characteristics of his interpretations is that he provides the general sum mary of the subjects of every chapter (surah) in the beginning to help the reader grasp a broader understanding of the topics of the chapter at hand. Also, he does not provide biased interpretation based on a specific denomination, but brings the words from all four schools of jurisprudence and other denominations. He believes that the Quran should not be interpreted with specific backgrounds of a certain belief.
che interpreted with spe-

Keywords: Tafsir, Zahrat-al-Tafasir, Abu Zahrah, Methodology, Interpretation.

Makalenin Gelis Tarihi: 04.11.2018; Makalenin Yayıma Kabul Tarihi: 07.12.2018

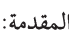

إن من أشرف الأعمال وأفضل القربات هي قراءة القر آن (الكريم) وفهم معانيه والتدبر في معارفه التها

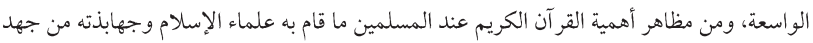

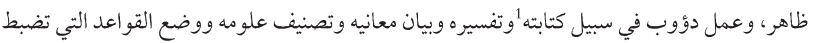

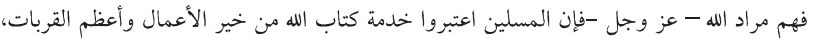

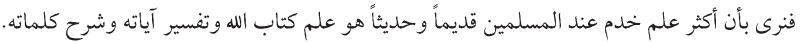
وأحد كتب التفسير التي ألفت في عصرنا هي تفسير القر آن الكريم لأبي زهرة، المشهور بزهرة

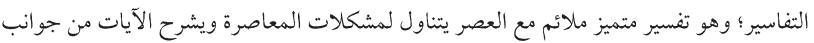

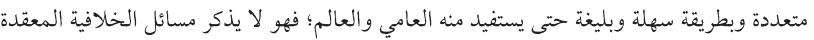

1 ينظر: الرواشدة، زياد عبد الرحمن، "المصحف الشريف في زمن الدولة العثمانية"، مجلة العلوم الإسلامية

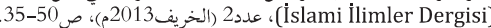


الجاهلية والإسلام، ثم كتب مؤلفًا عد الأول من نوعه في اللغة العربية، حيث لم تُفرد الخطابة قبله

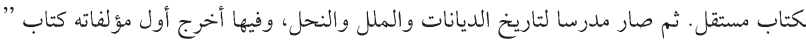

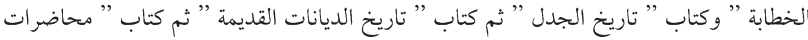

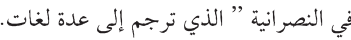

وقد تدرج أبو زهرة في كلية الحقوق التي شهدت أخصب حياته الفكرية حتى ترأس قسم الشريعة،

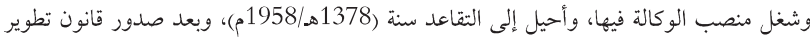

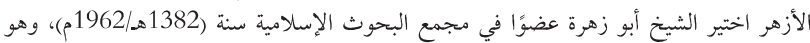

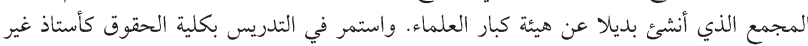

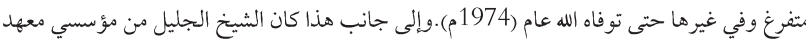
الدراسات الإسلامية بالقاهرة، وكان يلقي فيه محاضراته في الشريعة الإسلامية احتسابًا لله دون أجر.

2. 20. صفاته،سعة علمه ومنهجه:

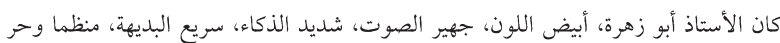

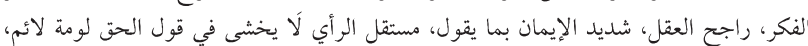

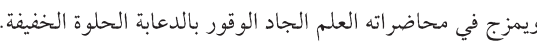

كان عالما متبحر افي الفقه وأصوله وفي علوم القر آن وتفسيره، وخطيبا مفوها، وأصوليا متعمقا،

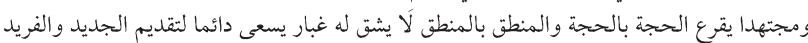

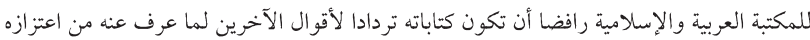

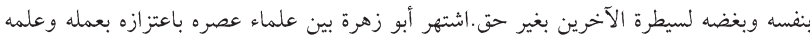

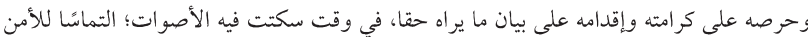

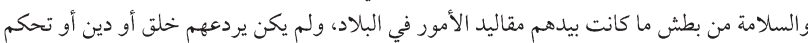
تصرفاتهم نخوة أو مروعة من بانت

كان رحمه الله يعيش للمبادئ ويكافح من أجلها، يناضل لعقيدة يحيا فيها ويعيش لها، يعلن

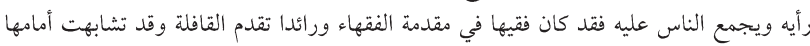

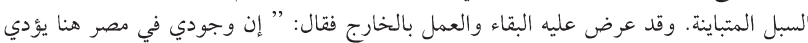

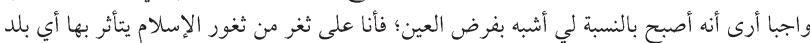

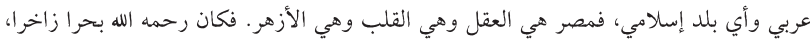

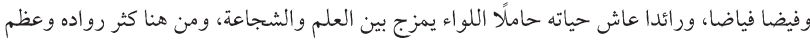

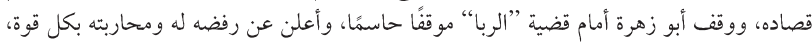

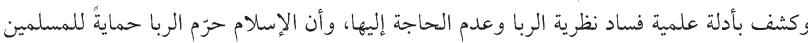

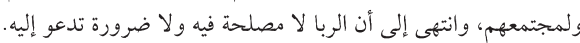

اقتضت طبيعة البحث أن يكون في مقدمة وثلاثة موضوعات رئيسية وخاتمة؛ على النسق الآتي: أو لاً: حياة الشيخ محمد أبو زهرة - رحمده الله - ومؤلفاته، وفيه أربع فروع:1. نشأته وحياته.2.

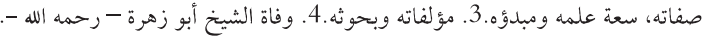
ثانياً: كتابه زهرة التفاسير. وفيه فرعان:1. التعريف بالكتاب.2. مصادره من كتب التفسير .ثالثاً:

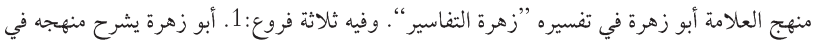

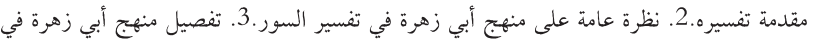

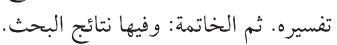

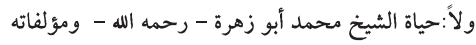

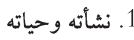

ولد محمد بن أحمد بن مصطفى بن أحمد المعروف بأبي زهرة في المحلة الكبرى التابعة

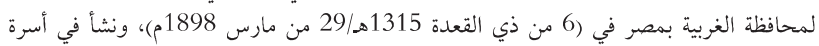

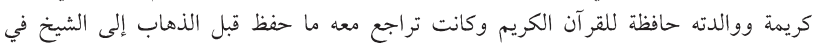

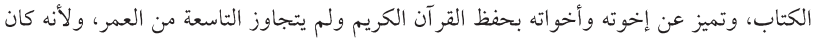

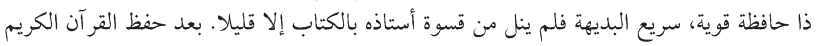

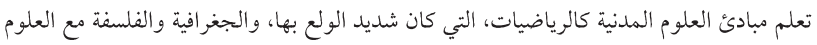

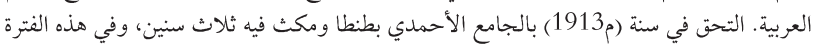
ابتدأ نبوغه وتفوقه.

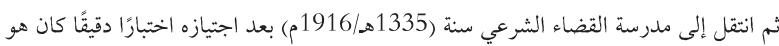

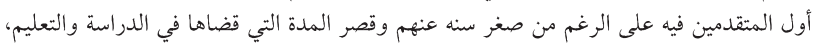

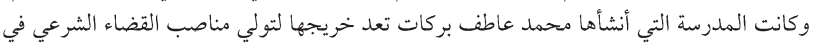
المحاكم المصرية.

وقد مكث فيها تسع سنين، أربعة في القسم الثانوي وخمسة في القسم العالي، وفيها اتسعت

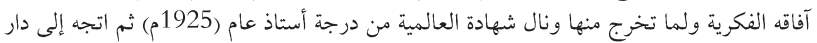

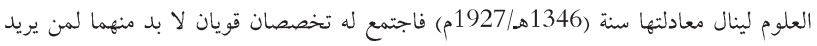

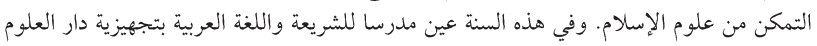

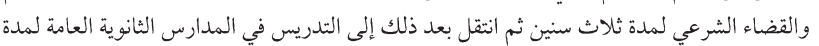

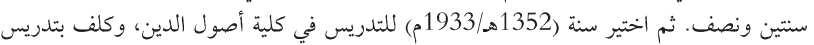
مادة الخطابة والجدل؛ فألقى محاضرات ممتازة في أصول الخطابة، وتحدث عن الخطباء في 


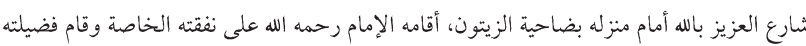

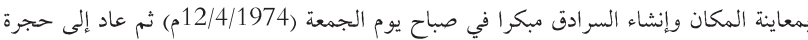

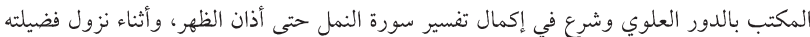

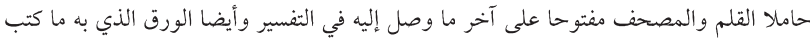

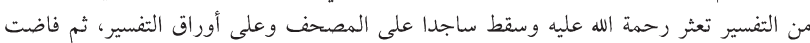

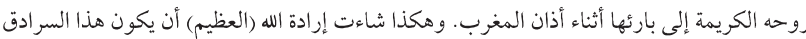

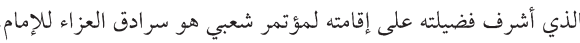

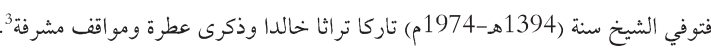

$$
\begin{aligned}
& \text { ثانياً: كتابه زهرة التفاسير } \\
& \text { 1.التعريف بالكتاب: } \\
& \text { أ. تسمية الكتاب: }
\end{aligned}
$$

لا يوجد دليل ولا نص - حسب بحثي- بأن الشيخ - رحمه الله - سمى تفسيره بزهرة التفاسير

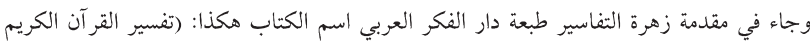

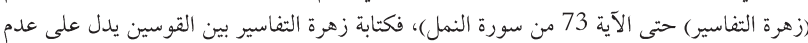
تسمية الشيخ أبو زهرة تفسيره بهذا الاسم.

ويحتمل عدم إكمال التفسير هو السبب الأساسي لعدم فرصة الشيخ لتسمية تفسيره.

وجدير بالذكر أن هناك تفسير لمحمد طاهر بن عبد القادر الكردي (المتوفي: 1400ه) سماه

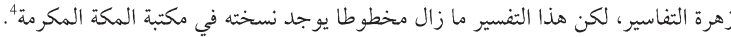

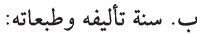

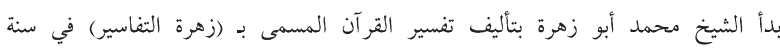

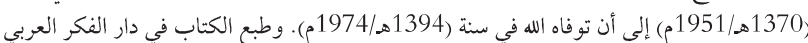

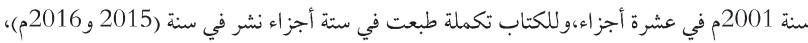

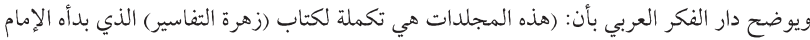

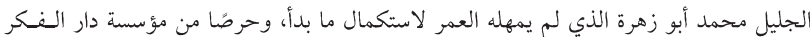

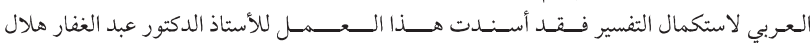

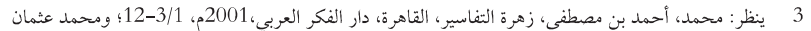

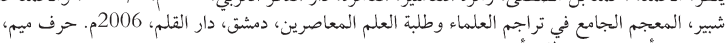

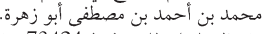

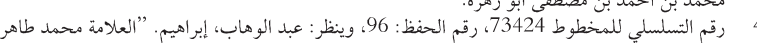

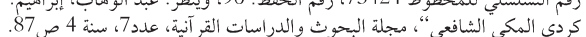

ووقف - رحمه الله - من قضايا المسلمين العامة كقضية الجزائر وقضية فلسطين وقفة الثائر

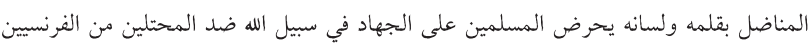
واليهود، ويجرم الاحتلال لبلاد المسلمين.

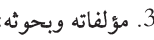

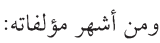

1-تاريخ المذاهب الإسلامية.2- العقوبة في الفقه الإسلامي.3- الجريمة في الفقه الإسلامي.4-

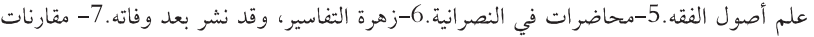

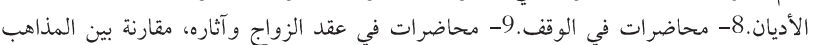

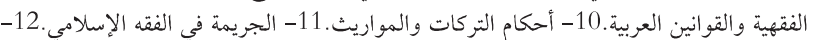

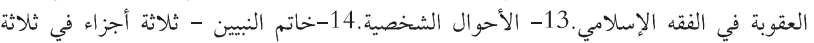

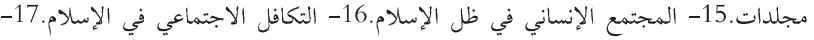
تفسير القرآن الكريم (زهرة الثفاسير).

كان لفضيلة الإمام نشاط واسع في محاضرات وندوات عامة في مختلف الجمعيات الاجتماعية

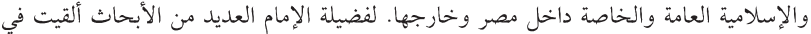

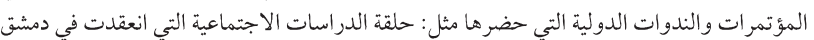

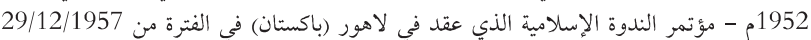

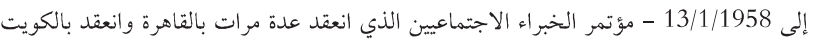

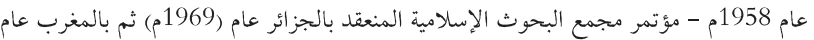

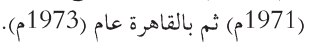

قام العديد من الباحثين بعمل رسائل ماجستير ودكتوراه عن الإمام محمد أبو زهرة في باكستان

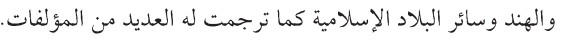

$$
\text { 4. وفاة الشيخ أبو زهرة - رحمه الله -: }
$$

عقد الإمام محمد أبو زهرة في أواخر عام (1973م) وأوائل عام (1974م) العديد من الندوات

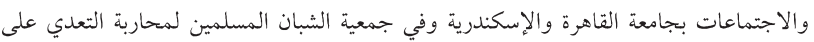

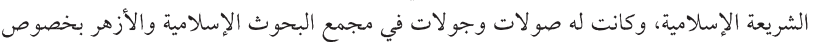

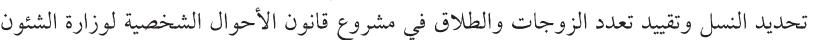

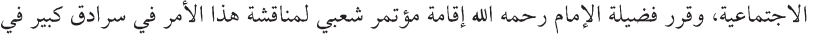

2 


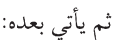

2- جامع البيان في تأويل القرآن،لمحمد بن جرير الطبري (المتوفى: 310هـ) 3- تفسير القر آن العظيم، لإسماعيل بن عمر بن كثير الدمشقي (المتوفى: 774هـ) 4- الجامع لأحكام القر آن،لمحمد بن أحمد القرطبي (المتوفى: 671هـ ) 5- مفاتيح الغيب، لمحمد بن عمر الرازي (المتوفى: 606هـ) 6- أنوار التنزيل وأسرار التأويل، لعبد الله بن عمر بن محمد الشيرازي البيضاوي (المتوفى: (685

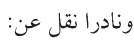
7- البحر المحيط،لأبو حيان محمد بن يوسف الأندلسي (المتوفى: 745هـ) 8- روح المعاني، لمحمود بن عبد الله الحسيني الألوسي (المتوفى: 1270هـ) 9- المحرر الوجيز، عبد الحق بن غالب بن عبد الرحمن الأندلسي المحاربي (المتوفى: (542

10- فتح القدير، لمحمد بن علي بن محمد بن عبد الله الشوكاني اليمني (المتوفى: 1250هـ) 11- إرشاد العقل السليم، لأبو السعود العمادي محمد بن محمد بن مصطفى (المتوفى: 982هـ) 12- محاسن التأويل محمد جمال الدين القاسمي (المتوفى: 1332هـ) أما المعاصرين فقدنقل عن الشيخ محمد عبده وتلميذه رشيد رضا من خلال: 13- تفسير القرآن الحكيم (تفسير المنار)، لمحمد رشيد بن علي رضا الحسيني (المتوفى: (1354

\section{ثالثاً:منهج العلامة أبو زهرة في تفسيره ”زهرة التفاسير“" 1. أبو زهرة يشرح منهجه في مقدمة تفسيره:}

اختار العلامة أبو زهرة في تفسيره منهجا واضحا يشرح أصوله في افتتاحية كتابه فيقول: (وإنه

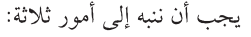

أولها: أننا لا نتجه إلى الأغاريب إلا إذا اضطررنا لتوجيه المعاني وتقريب الناس من إدراكها، وإن ذلك نادر، وليس بالكثير.

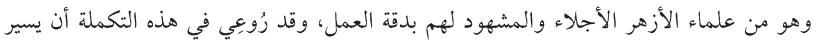

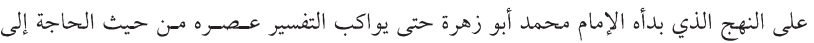

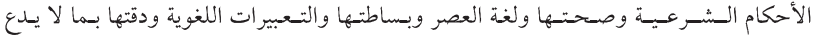

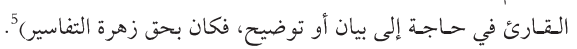

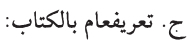

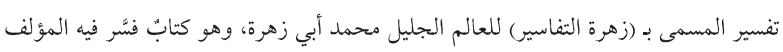

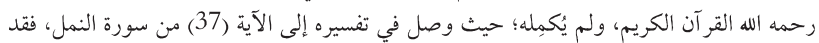
أدركه الموت قبل إتمامه.

بدأ الشيخ أبو زهرة بنشر تفسيره لآيات من القرآن الكريم في مجلة لواء الإسلام في (ذي القعدة

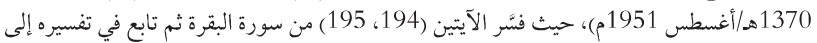

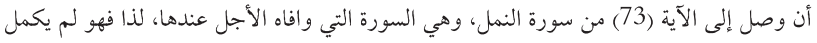

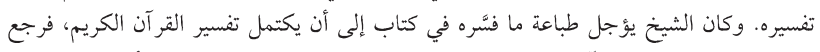

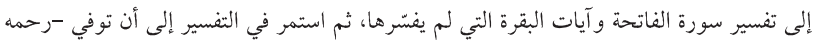

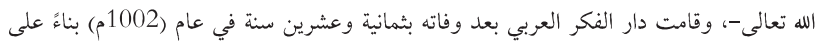

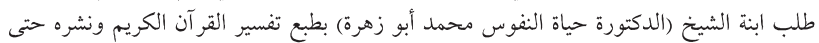

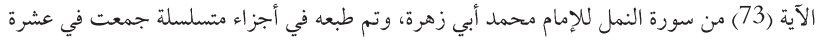

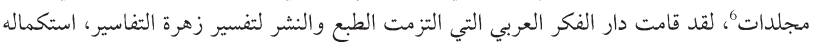

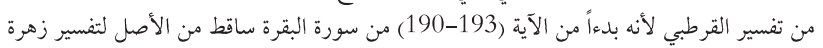

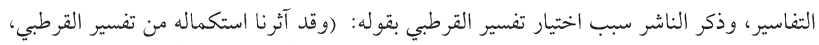

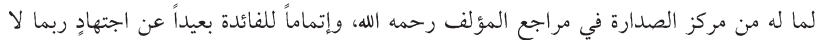

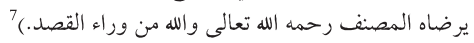

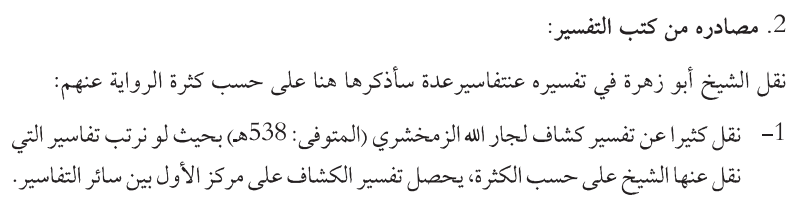

http://www.darelfikrelarabi.com موقل 5 7 
لأحكام الإلهية فهو كان يعيش في فترة وصل الإعجاب بالغرب والانبهار بحضارته إلى قمثه؛ فمثلا

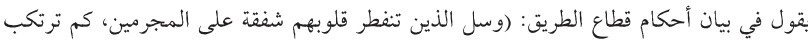

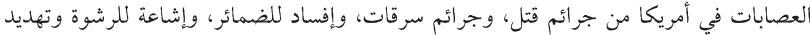

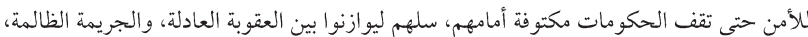

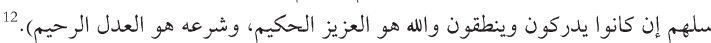

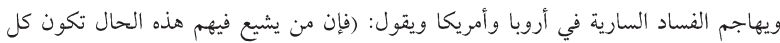

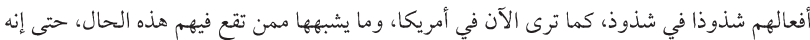

في إنجلترا يعترف بأن للشاب أن يتزوج الشاب، وتحترم هذه العلاقة الشاذة.

$$
\text { 3. تفصيل منهج أبي زهرة في تفسيره: }
$$

أ. منهجه في عرض المواد اللغوية وشرحها:

لا يدخل الشيخ في تفاصيل اللغة لكل كلمات الآية بل يشرح الكملة لغة إذا توجد هناك

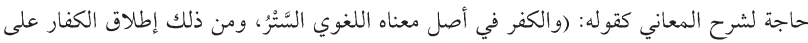

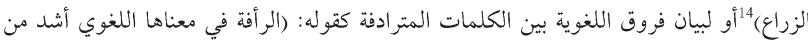

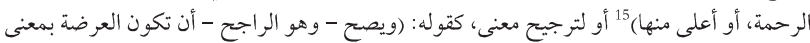

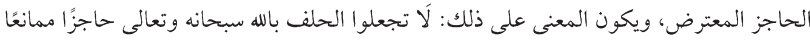

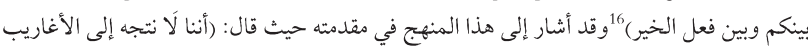

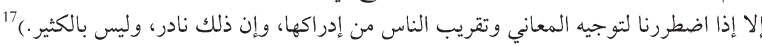
وجدير بالذكر أن الشيخ يشرح بعض الكلمات في تفسيره على أساس استعماله في القرآن

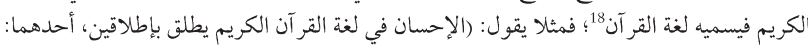

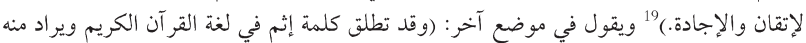

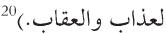

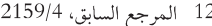

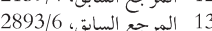

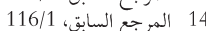
445/1 المرجع السبقع السبق، 15

16 المرجع السايق، 15

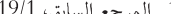

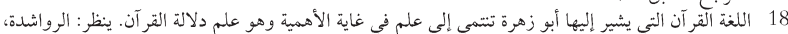

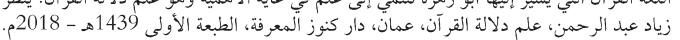

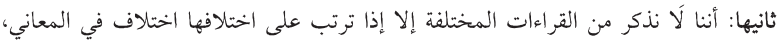

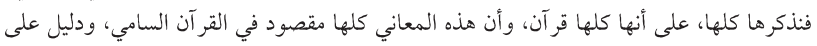

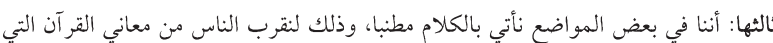

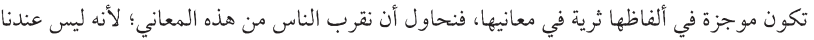
طاقة هذا الإيجاز البليغ الذي هو من في دلائل الإعجاز

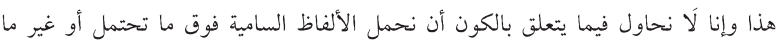

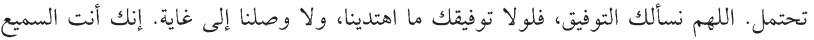

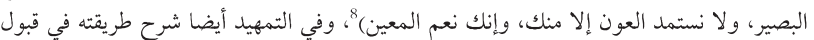
الأحاديث ونظرته في تفسير القر آن بالرواية أو بالر أي. نالي.

$$
\text { 2. نظرة عامة على منهج أبي زهرةفي تفسير السور: }
$$

الناظر إلى زهرة التفاسير يعرف بوضوح منهج الشيخ أبو زهرة في تفسير السور إجمالا فإنه لا

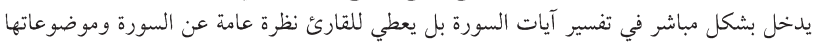
قبل أن يفسر الآيات بشكل تفصيلي. وهو يصرح بهذا المنهج في بداية تفسيرهلسورة النساء النساء فيقول:

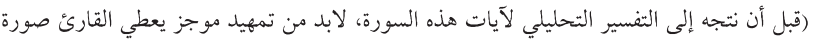
لما اشتملت عليه)

فهو يذكر في بداية السورة مكية السورة أو مدنيتها، ثم يذكر عدد آيات السورة إلا في أربع سور

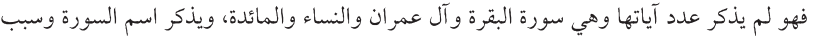

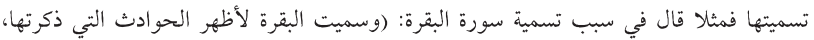

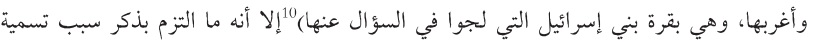

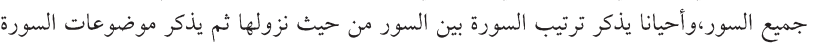
بشكل عام.

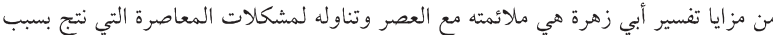

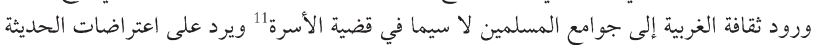

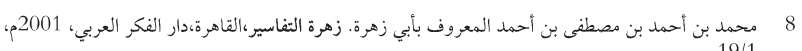

9

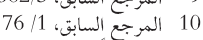

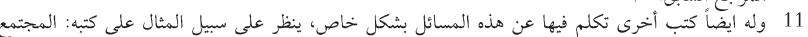
الإنساني في ظل الإسلام، تنظيم الأسرة وتنظيم النسل والتكافل الإسلامي في الإنس علئ الإسلام 


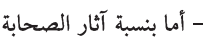

فهو يقول: (ونأخذ بأقو ال هؤلاء على أساس ألا تخالف نصا قر آنيا، أو تناهضه، أو تحمله ما

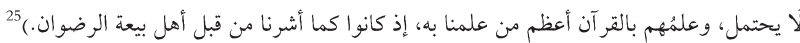
ويقول: (فقد كان ابن عباس ترجمان القر آن كما عبر بعض علماء الصحابة، وقد أخذ من علم كثير من الصحابة، وخصو صا ابن عمله عليًّا.) - روايات التابعين:

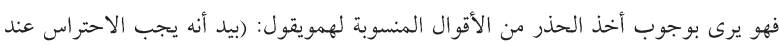

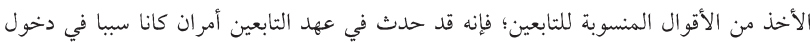

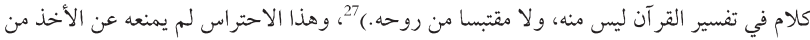

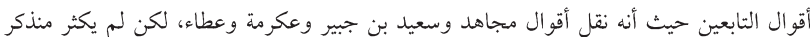

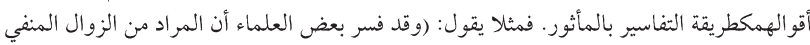

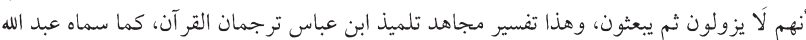

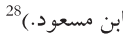
ويقول: (وقد قال عطاء في هذا: إنهم للمؤمنين كالولد لوالده والعبد لسيده، وعلى الكافرين

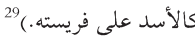
ج. منهجه في العقيدة:

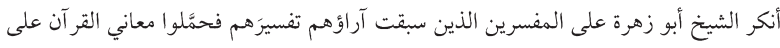

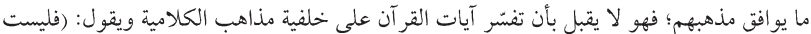
معاني القر آن أشعرية ولا ماتريدية، ولا اعتز الية.

لكن هذا القول ليس بمعنى أنه لا ينقل آرائه في علم الكلام ولا يتناول المباحث العقيدة أصلاً،

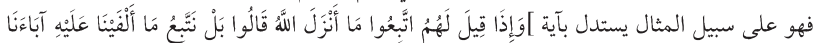

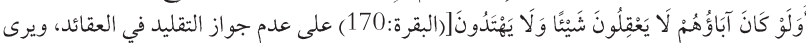

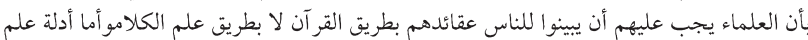
الكلام فهي كالدواء الذي يعطي بقدر لمن أصيبوا في عقيدتهم. 25/1 25 المرجع السابق، 25 26 المرجع السابق، 25/1 الساب، 25/1 27 المرجع السابق، 26,25/1 السبق، 28 المرجع السابق، 28 29 30 المرجع السابق، 39/1 31

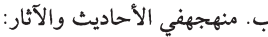
- منهجه في قبول ورد الأحاديث:

يذكر المؤلف - رحمه الله - الأحاديث غالبا لشرح بعض الآياتأو لتبيين جزء منها وأيضا

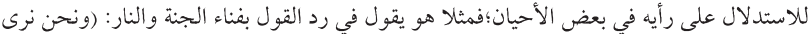

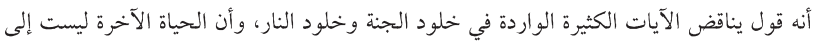

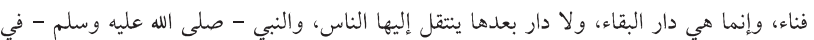

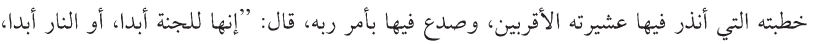

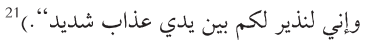

وأما منهجه في رد الأحاديث، سوى موضوع ضعف السند، هو : رد الأحاديث التي تخالف القر آن فهو

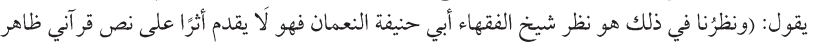

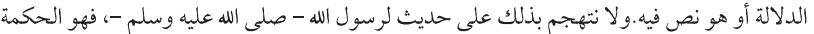

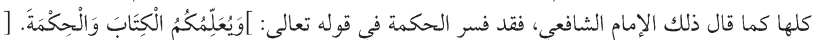

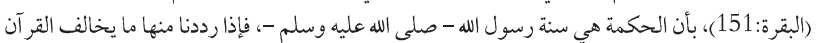

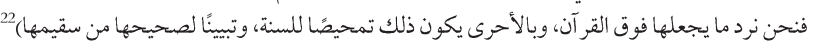
بناء على ذلك، فهو يرد الروايات التي تقول بأن الرسول - صلى الله عليه وسلم - سحر بقوله:

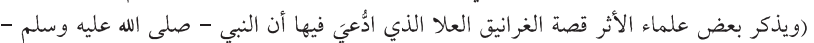

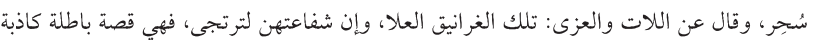

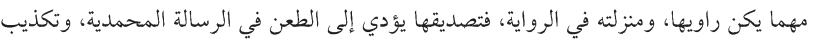

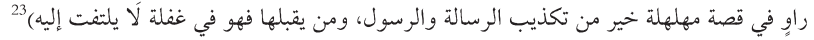

$$
\text { - رد أحاديث الآحاد التي تناقض العقل والعلم القطعي والحس: }
$$

فهو يقول: (بيد أنه في بعض المروي عن النبي - صلى الله عليه وسلم - ما يخالف ما نحسه

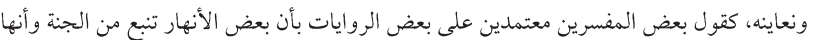

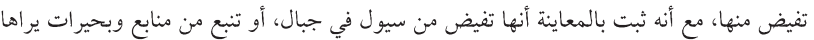

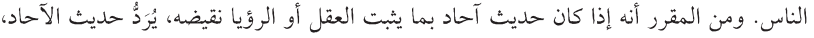

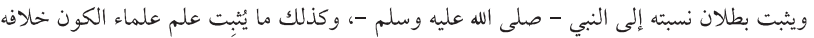

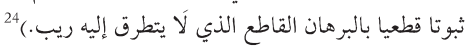

2 26 المرجع الساتق، 2668/5 22 المرجع السابق، 24 المرجع، 24/1 المرابق، 23 المرجع السابق، 5005/9 24 المرجع السابق، 28/1 


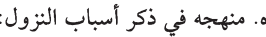

هو يذكر أسباب النزول لتأكيد معنى الذي رجحه في تفسيره، فمثلا يقول: (والأمر الأول هو النه

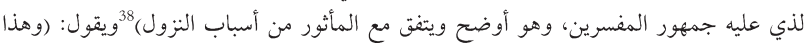

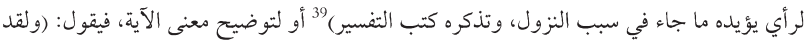

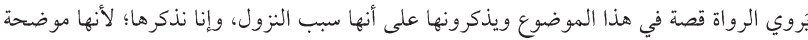

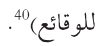

$$
\text { و. منهجه في الناسخ والمنسوخ: }
$$

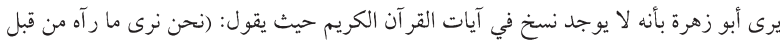

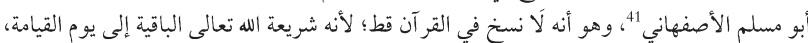

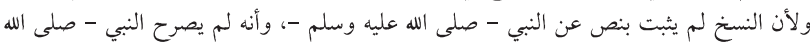

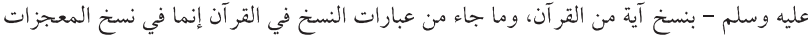

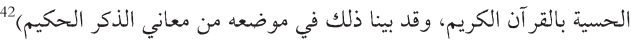
فهو يرى بأن النسخ بنسبة للقر آن الكريم هو نسخ الشرائع السابقة

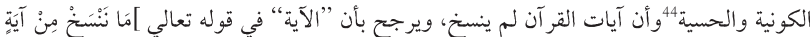

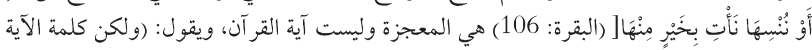

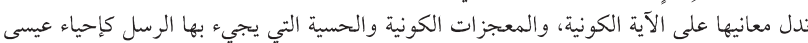

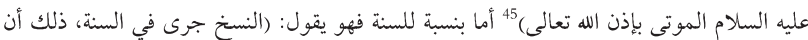

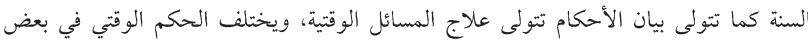

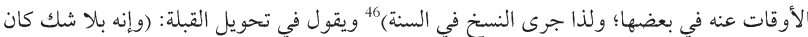

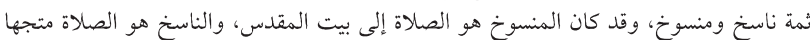

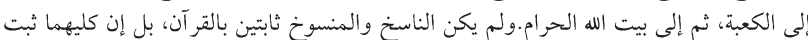

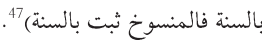

38 39 المرجع السابق، 2239/4 40 المرجع السابت، 2389/5 الساب،

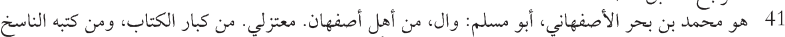

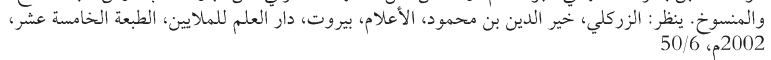
42 4المرجع السابق، 41/1 43 ينظر: المرجع السابق 42 44 الذمرجع السايق، 354/1 45 المرجع السابق، 45 46 المرجع السابق، 40/1 45

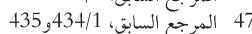

هو أيضا عندذكر موضوعآيات المتشابه، يذكر اختلاف علماء العقيدة و آرائهم في آيات الصفات

$$
\text { التي توهم التشبيه. }
$$

د. منهجه في بيان القراءات:

لا يذكر جميع القراءات الواردة للآيات بل يذكرها إذا ترتب على اختلافها، اختلاف في المعاني

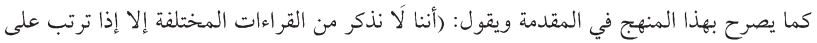

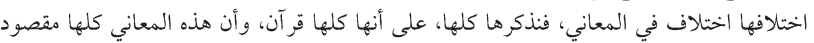
في القر آن السامي، ودليل على إعجازه.

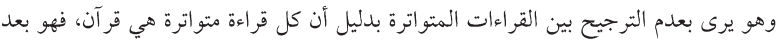

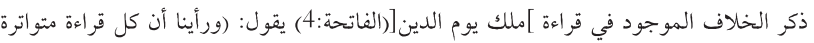

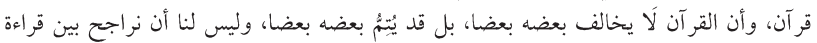

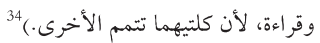

ويرى الشيخ - رحمه الله - بأن (قراءات القرآن المتواترة فوق قواعد النحاة، وهي أصدق في الني الفصحى.)

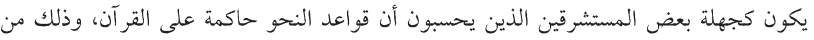

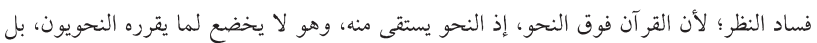

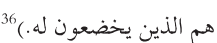

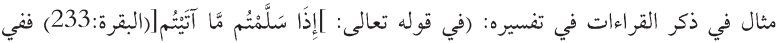

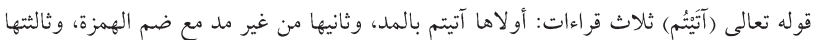

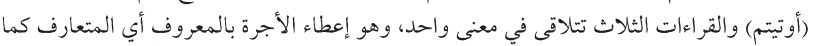

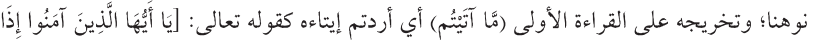

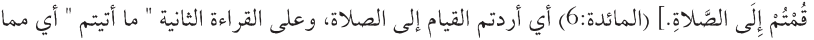

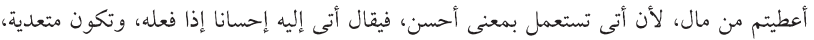

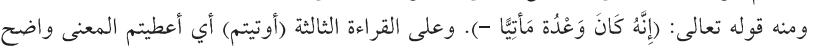
33 المرجع السابق، 32

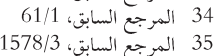
36 35 المرجع السابق، 2295/5 السابق، 37 زهرة الثفاسير، 813/2 
الأرض فكيف يشبت ما دونها بالقر آن القطعي بدلالته وسنده، ولا تثبت تلك العقوبة الغليظة إلا

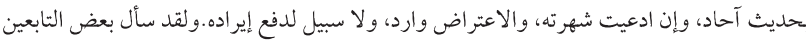

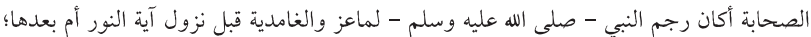

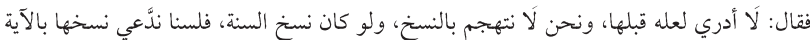

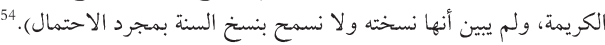

فهو يقول في هذا الموضع: نحن لا نتهجم بالنسخ ويقول: فلسنا ندعي نسخها بالآية الكريمة.

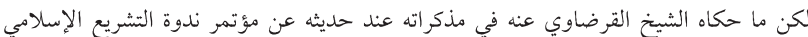

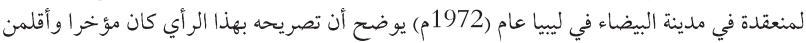

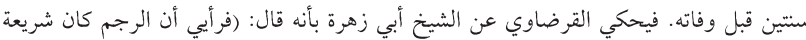

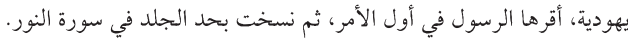
قال الشيخ: ولي على ذلك أدلة ثلاثة:

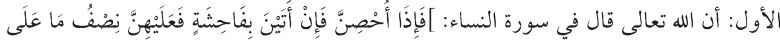

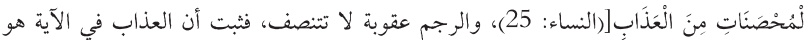

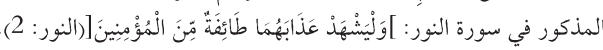

والثاني: ما رواه البخاري في (جامعه الصحيح)"، عن عبد الله بن أوفى: أنه سئل عن الرجم؟ هل

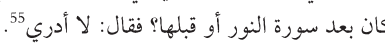

فمن المحتمل جدًا أن تكون عقوبة الرجم كانت مقررة قبل نزول آية النور التي نسختها.

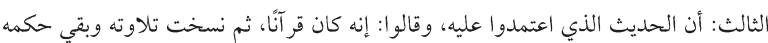

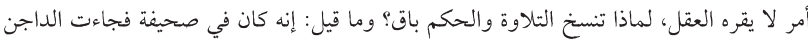

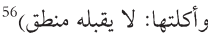

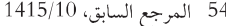

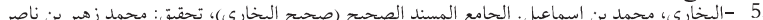

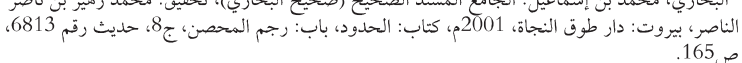

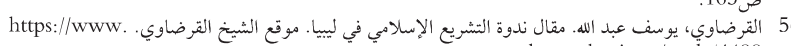
al-qaradawi.net/node/4488
ز. منهجه في ذكر آراء الفقهاء وآيات الأحكام:

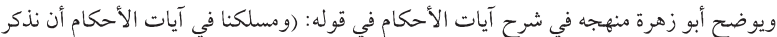

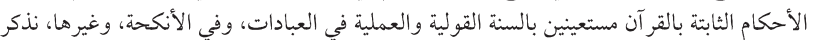

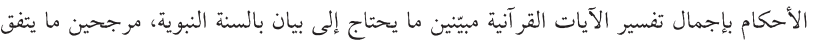

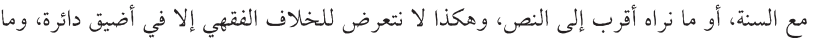

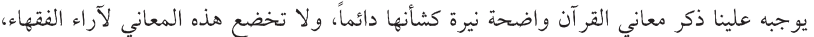

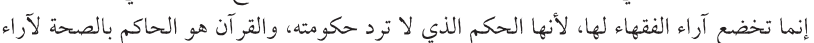
الفقهاء وليس محكوماً بها) يذكر الشيخ في آيات الأحكام أقوال مذاهب الأربعة عموما وأيضا يذكر في بعض الأحيان أقوال

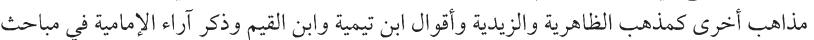

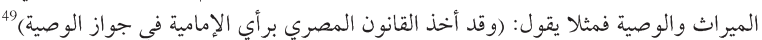
ورغم أن أبو زهوة كان على مذهب أبي حنيفة - رحمهما الله -وصرح بذلك في مقال منهاج

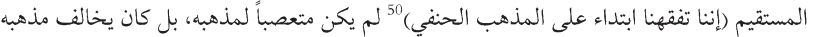

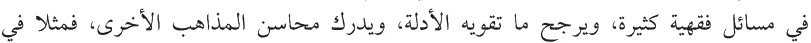

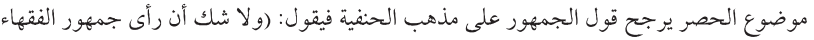

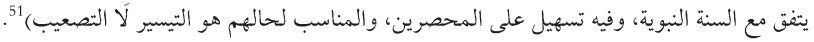
وفي موضوع مدى إلزام الأم بإرضاع طفلها، يرى بأن رأى الحنفية ينافي قول الله تعالى: أوَّانْ

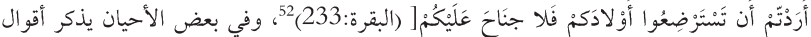

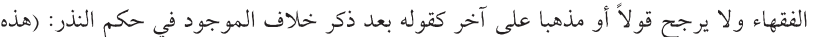
كلمة إجمالية في حكم النذر واختلاف أقو الال الفقهاء فيه)

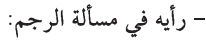

من ضمن آراء الفقهية التي اشتهرت عن الشيخ أبي زهرة هي مسألة الرجم.فإنه كان يرى بأن أنمان

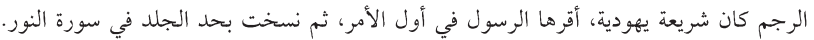

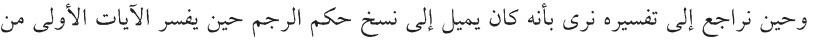

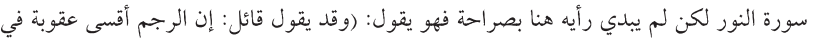

48

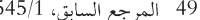

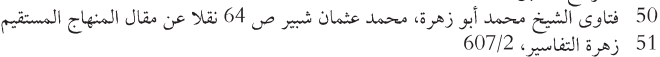
52

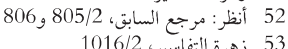




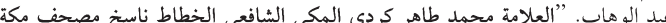

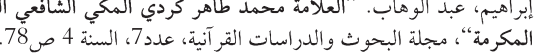

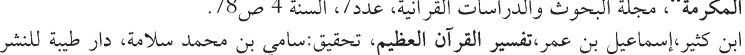

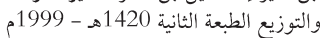

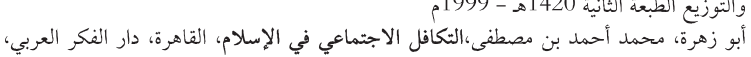
1991

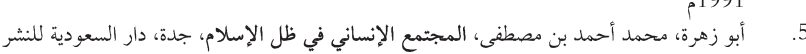

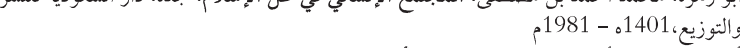
6. أبو زهرة، محمد أحمد بن مصطفى،تنظيم الأسرة وتنظيم النسل، القاهرة، دار الفكر العربي،1396ه 1976-

7.

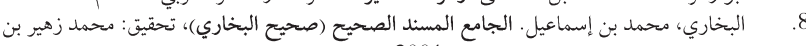

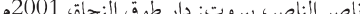

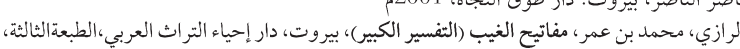
1420

الرواشدة، زياد عبد الرحمن، علم دلالة القرآن، عَمان- الأردن، دار كنوز المعرفة، الطبعة الأولى

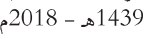

الرواشدة، زياد عبد الرحمن، المصحف الشريف في زمن الدولة العثمانية، مجلة العلوم الإسلامة

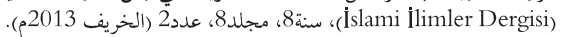

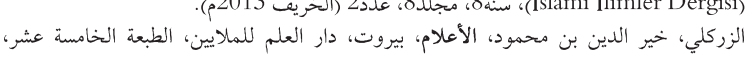

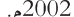
الزمخشري، محمود بن عمرو بن أحمد،الكشاف عن حقائق غوامض التزيل، بيروت، دار الكتاب

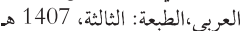

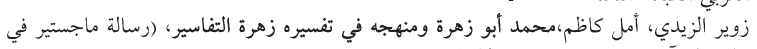

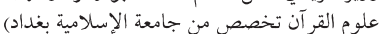

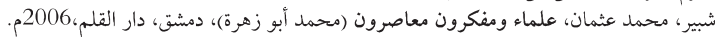

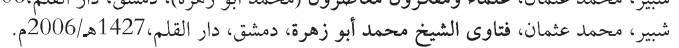

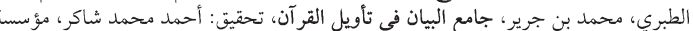

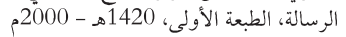
عبده زراره،منار فتحي،منهج الإمام محمد أبو زهرة في التفسير، (رسالة لنيل درجة ماجستير من

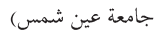

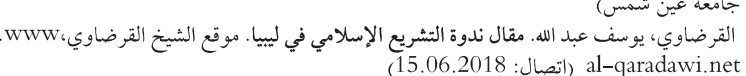

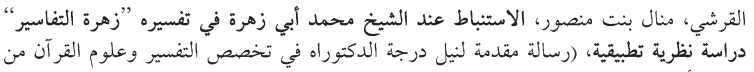

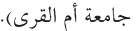

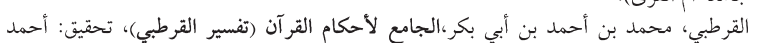

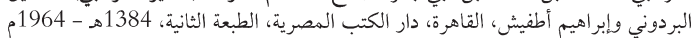

وأخيراً وصلت إلى أنه كتب تفسيره بمنهج معاصر،واستفاد لشرح الآيات من علوم اللغة العربية

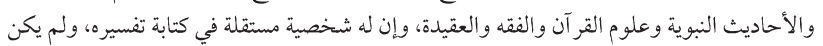

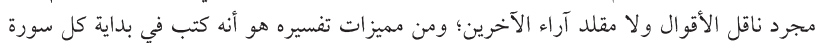

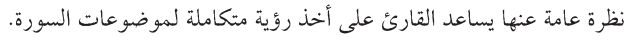

وهنا أذكر أهم نتائج البحث: إن تفسير زهرة التفاسير هو تفسير متميز ملائم مع العصر يتناول

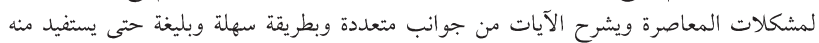

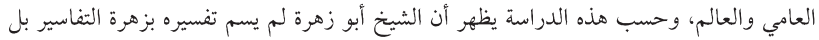

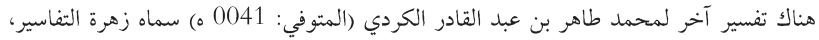

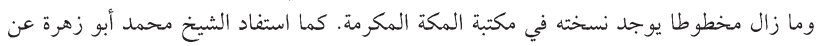

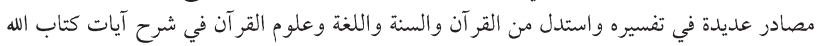

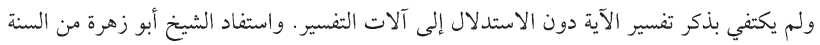

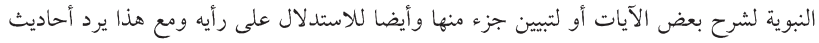

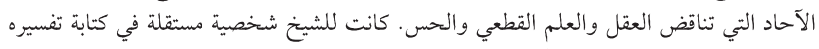

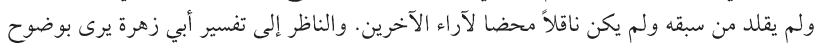

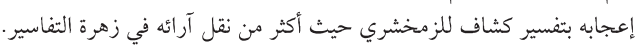

إن الشيخ محمد أبو زهرة لم يتعصب في تفسيره على مذهب فقهي معين بل جاء بأقو ال الأئمة

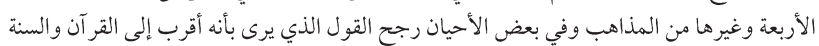

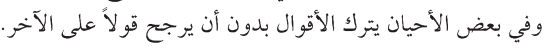

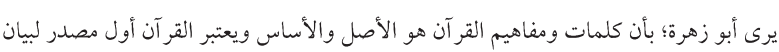

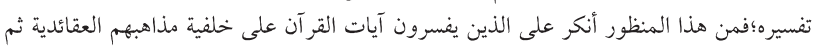

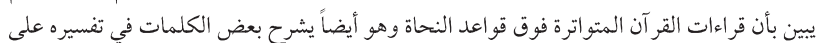

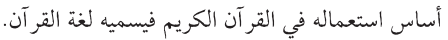




\section{Kaynakça}

1. Kur'ân-1 Kerîm

2. İbrahim, Abdülvehhab, Muhammed Tâhirel-Kürdî el-Mekkî, Bühûs ve Dirâsât Dergisi, sayı: 7, Y:4, s.87.

3. İbn Kesir, İsmail İbn Ömer, Tefsirü'l-Kur'ani'l-Azim, thk. Sâmî bin Muhammed es-Selâme, Daru Taybe, II. Basım 1420/1990.

4. Ebu Zehra, Muhammed b. Ahmed b. Mustafa, el-Tekaful el-İctimai fi'l-İslam, Káhira, Darü'l-Fikri'l-Arabi, 1991.

5. Ebu Zehra, Muhammed b. Ahmed b. Mustafa, el-Müctemaü'l-İnsânî fi Zilli'lİslam, Cidde, Darü'l-suudıa lil neşr, 1976.

6. Ebu Zehra, Muhammed b. Ahmed b. Mustafa, Tanzìm al-Usra ve Tanzīm alNasl, Káhira, Darü'l-Fikri'l-Arabi, 1396/1976.

7. Ebu Zehra, Muhammed b. Ahmed b. Mustafa, Zehratu't-tefâsir, Káhira, Darü'lFikri'l-Arabi, 2001.

8. El-Buhâri, Ebu Abdullah Muhammed b. İsmâil, Sahih Buhari, Thk. Muhammad Zuhair bin Nasir al-Nasir, Beyrut, Dar Tüvk El-nicah, 2001.

9. Razi, Fakhr al-Din Muhammad ibn 'Umar, Mafatih al-Ghayb, Beyrut, Daru İhya et-Turas el-Arabi, III. Basım, 1420.

10. Alrawasdah, Ziyad, İlmu Dilalet el-Kuran (Qur'anic Semantics), Amman, Dar el-Konuz el-Marifa, 1439/2018.

11. Alrawasdah, Ziyad, el-Mushaf el-Şerif fi Zemen el-Devlet el-Osmani, Ankara, İslami İlimler Dergisi, Yıl: 8, Cilt. 8, Sayı. 2, Güz 2013.

12. ez-Ziriklî, Hayreddin b. Mahmud, el-A'lâm, Beyrut, Darül Alem li'l-melayin, 2002.

13. ez Zemahşeri, Mahmud b. Ömer, el-Keşşâf, Beyrut, Darül kitab el-Arabi, III. Basim, 1407.

14. Züvaır Ez Zeidi, Emel Kazım, Muhammed Ebu Zehra ve Menhecohu Fi Tefsirehi Zehratu't-Tefâsir, (Yüksek Lisans Tezi, Bağdat Üniversitesi).

15. Şebir, Muhammed Osman, Ulama, Ulema vel Mufakkırun el-Muasırun (Muhammed Ebu Zehra), Demeşk, Darül kalem, 2006.

16. Şebir, Muhammed Osman, Fetava eș Şeih Muhammed Ebu Zehra, Demeşk, Darül kalem, 2006.

17. el-Karadavi, Yusuf Abdullah, Nedvet et'teșrii el-islami Fi libiya (makalesi): www.al-qaradawi.net (Erişim: 15.06.2018).

18. et-Taberî, Muhammed Bin Cerir, Camiul Beyan an Tevili Ayil Kuran, Thk. Ahmed Muhammed Şakir, Muassasah al-Risalah, 1420/2000.

19. Abde zürareh, Minar Fethi, Menhec El-imam Muhammed Ebu Zehra Fit'tefsir, (yüksek lisans tezi, Ayn Şems Üniversitesi).

20. el-Küreși, Menal bt. mensur, el-İstinbat inde'ş-Şeih Muhammed Ebi Zehra Fi Tefsirehi Zehratu't-tefâsir, (Doktora tezi, Ummul Kura Üniversitesi).

21. Kurtubi, Ebu Abdullah Muhammed b. Ahmed, el-Cami li Ahkami'l-Kur'an, Thk. Ahmed el-Berduni ve İbrahim Etfiş, Káhira, Darül kütüb el-misriyeh, II. Basim,1384/1964. 